\title{
An Unusual Case of Appendiceal Adenocarcinoma Presenting with Rectal Bleeding and Haematuria
}

\author{
John A. Murphy Nagy Matar \\ Department of Surgery, Southport and Ormskirk NHS Trust, Southport, UK
}

\section{Key Words}

Appendiceal adenocarcinoma $\cdot$ Colovesical fistula $\cdot$ Enterocolic fistula

\begin{abstract}
Adenocarcinoma of the appendix is rare, usually being diagnosed intraoperatively when performing appendicectomy or at subsequent histological examination. Here we report a case with acute abdominal pain, rectal bleeding with haematuria being the presenting symptoms. Subsequent computerised tomography demonstrated a complex mass involving the ileum, right colon, sigmoid colon and bladder with inflammatory bowel disease being the most likely cause. At laparotomy a right hemicolectomy, sigmoid colectomy and partial cystectomy was performed with pathological specimens confirming an appendiceal adenocarcinoma as the primary source of the abdominal mass fistulating into adjacent structures. We conclude that although appendiceal tumours are rare - usually diagnosed at appendicectomy, they should be considered in the diagnosis of complex abdominal masses involving small bowel, large bowel and adjacent pelvic structures.
\end{abstract}

\section{Introduction}

Tumours of the vermiform appendix are rare, accounting for $0.4-1.0 \%$ of all gastrointestinal malignancies. They are more common in men, with the highest incidence in the fifth decade of life [1]. They are commonly diagnosed histologically following appendicectomy with carcinoid of the appendix being most common. Other diagnoses include adenocarcinoma of the appendix, mucocoele (pseudomyxoma peritonei) and lymphoma, however only $0.7-1.7 \%$ of appendicectomy specimens contain neoplastic lesions [1]. Here we present an unusual case of appendiceal carcinoma presenting in a young male with acute abdominal bleeding, a palpable mass with bleeding per rectum and haematuria. 


\section{Case Report}

A 38-year-old white male patient was admitted as an emergency complaining of a 2-day history of abdominal pain, with fresh red bleeding per rectum occurring 3 times a day in small quantities. He had also noticed a 1-day history of frank haematuria. He had no medical history of note prior to this episode. On admission he was febrile with a temperature of $38.1^{\circ} \mathrm{C}$, tachycardia of 110 beats $/ \mathrm{min}$, but was normotensive. Abdominal examination revealed a tender palpable mass arising centrally in the lower abdomen with no peritonism. Rectal and genital examination as well as initial plain radiographs were unremarkable. However he was anaemic with a $\mathrm{Hb}$ of $9.7 \mathrm{~g} / \mathrm{l}$ with a slightly raised WCC of $13.8 \mathrm{~g} / \mathrm{l}$ and a raised C-reactive protein of $57 \mathrm{~g} / \mathrm{l}$. Other baseline haematological parameters were within the normal range. He went on to have an urgent computerised tomography (CT) scan which demonstrated a large mass in the lower abdomen, involving the sigmoid and adjoining terminal ileal loops of the small bowel. There was a central area of necrosis/abscess formation extending into the surrounding mesenteric fat (fig. 1a). The mass extended to and involved the dome of the bladder. The hypodense areas contained small bubbles suggesting abscess formation and probable fistulous connection to the bowel loops. Differential diagnosis included Crohn's disease, perforated sigmoid malignancy, primary small bowel malignancy or lymphoma (fig. 1b). Following a period of resuscitation he was taken for laparotomy. A complex mass was found involving the caecum, appendix and terminal ileum, adherent to the bladder and sigmoid colon. An en bloc resection was performed aiming for curative resection including a right hemicolectomy, left/sigmoid colectomy with partial cystectomy and a covering loop ileostomy proximal to the ileocolic anastomosis. There was no evidence of metastatic spread within the abdominal cavity. Postoperatively the patient made an uneventful recovery and was discharged home one week later.

Macroscopic investigation of the specimen revealed a complex tumour mass containing the aforementioned specimens. The proximal end of the appendix was normal. However, the distal end was expanded and merged with the main tumour mass involving both small and large bowel and bladder. Microscopic examination revealed a moderately differentiated, partly mucinous adenocarcinoma of the appendix involving the small bowel, sigmoid colon and bladder serosa/adventitia with no extramural vascular invasion. There were no positive lymph nodes in the specimen. The main tumour appeared to be arising from an adenoma of the appendix, which generally demonstrated mild to moderate dysplasia but towards its distal end (merging with the main tumour) showed severe dysplasia including a large polypoid component. As this was an adenocarcinoma of the appendix, it was finally staged as Duke's B or TNM pT4b N0 Mx with complete resection margins.

The patient required adjuvant chemotherapy for 6 months and had the loop ileostomy reversed 10 months later. He is currently well with no evidence of recurrent disease on recent CT.

\section{Discussion}

Neoplasms of the appendix are rare, accounting for less than $0.5 \%$ of all gastrointestinal malignancies. Most appendiceal tumours present as appendicitis, pelvic abscess or incidental findings at laparotomy. Very occasionally they present with bowel obstruction, carcinoid syndrome or inflammatory bowel disease $[2,3]$ and rarely the appendiceal carcinoma penetrates the bladder or causes ureteric obstruction $[4,5]$. However, this case appears to be the first presenting with both haematuria and new-onset bleeding per rectum.

Management of appendiceal neoplasms should follow sound oncological surgical principles. Murphy et al. [1] suggested that for tumours found incidentally at laparotomy, confined to the appendix, smaller than $2 \mathrm{~cm}$ and not involving the base of the appendix or mesoappendix, appendicectomy is appropriate. Any neoplasm greater than $2 \mathrm{~cm}$ involving the base of the appendix or mesoappendix should undergo full or limited right hemicolectomy for optimal outcome. If the patient presents electively, routine tumour markers including CEA, CT scanning and colonoscopy should be performed [6]. In the emergency setting this may be inappropriate, but should there be any doubt in the diagnosis, a baseline CT scan can usually be obtained prior to surgery. Depending on the 


\begin{tabular}{r|l|l|l} 
Case Reports $/ \mathrm{h}$ & $\begin{array}{l}\text { Case Rep Gastroenterol 2009;3:265-268 } \\
\text { D01: 10.1159/000234906 }\end{array}$ & Published online: August 28, 2009 & $\begin{array}{l}\text { O 2009 S. Karger AG, Basel } \\
\text { ISSN 1662-0631 } \\
\text { www.karger.com/crg }\end{array}$ \\
\hline
\end{tabular}

stage and grade of the tumour, the overall 5-year survival reported for adenocarcinoma of the appendix is around $55 \%$.

\section{Conclusion}

Appendiceal neoplasms are rare and usually present with symptoms of appendicitis [7], but can present in a wide variety of unusual ways, including lower colonic and urological symptoms. Examination of the appendix should be considered as routine during laparotomy, with appendicectomy or limited right hemicolectomy performed if appropriate. This should be remembered when junior surgeons are consenting patients so that the patient can be forewarned prior to appendicectomy or laparotomy in order to avoid potential litigation.

Fig. 1. a CT scan demonstrating a complex mass, arising in the lower abdomen, incorporating the caecum, small intestine and sigmoid colon. $\mathbf{b}$ The mass is also seen adherent to the dome of the bladder with gas present.
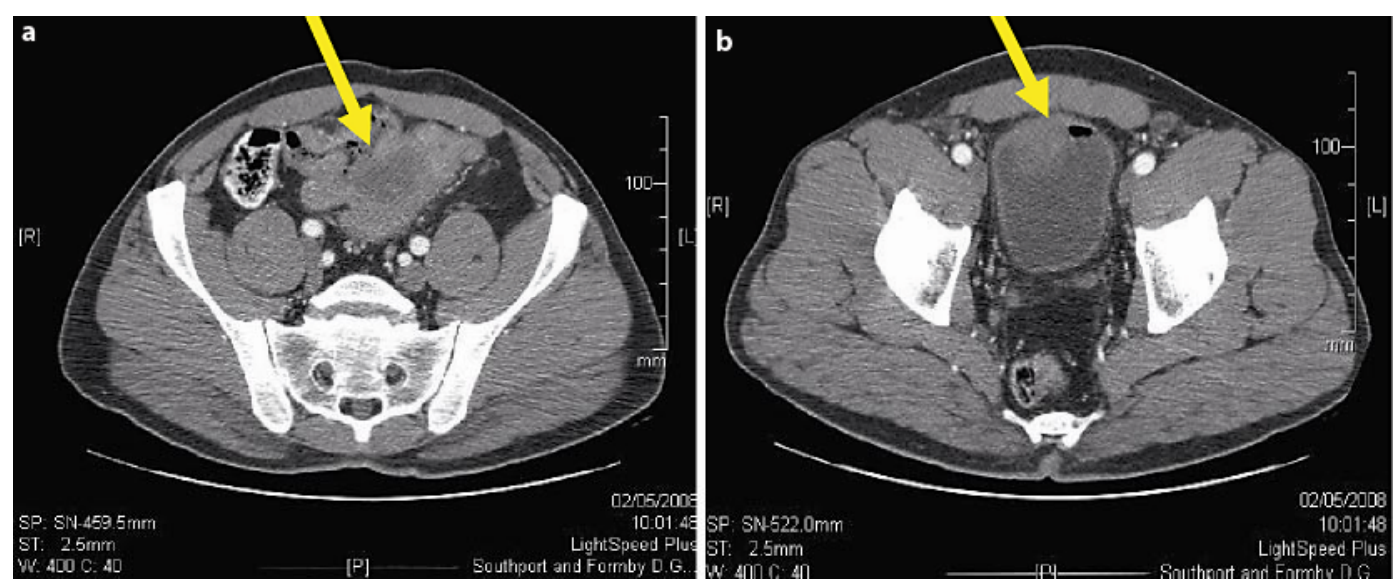


\section{References}

1 Murphy EM, Farquharson SM, Moran BJ: Management of an unexpected appendiceal neoplasm. Br J Surg 2006;93:783-792.

2 Aljarabah MM, Borley NR, Wheeler JM: Appendiceal adenocarcinoma presenting as left-sided large bowel obstruction, a case report and literature review. Int Semin Surg Oncol 2007;4:20.

-3 Ahmed K, Hoque R, El-Tawil S, Khan MS, George ML: Adenocarcinoma of the appendix presenting as bilateral ureteric obstruction. World J Surg Oncol 2008;6:23.

4 Rahman SI, Matthews LK, Townell NH: Appendicular adenocarcinoma leading to appendiculo-vesical fistula. Br J Urol 1996;78:305-306.

5 Bischoff W, Böhm N: Adenocarcinoma of the appendix penetrating the bladder. J Urol 1980;123:123.

6 Hu CC, Chang JJ, Chen TC, Yen CL, Chien RN: Colonoscopic feature of primary adenocarcinoma of the appendix. Intern Med 2008;47:255-257.

7 Connor SJ, Hanna GB, Frizelle FA: Appendiceal tumors: retrospective clinicopathologic analysis of appendiceal tumors from 7,970 appendectomies. Dis Colon Rectum 1998;41:75-80. 